\title{
Kuwait Acute Coronary Syndromes Registry: Baseline Characteristics, Management Practices and In-Hospital Outcomes of Patients Hospitalized with Acute Coronary Syndromes in Kuwait
}

\author{
Mohammad Zubaid ${ }^{a}$ Wafa A. Rashed ${ }^{c}$ Hisham Saad ${ }^{c}$ Ali Attiya $^{c}$ \\ Bassam Abu Al-Banat $^{d}$ Mustafa Ridha ${ }^{e}$ Muhammad H. Al-Kandari ${ }^{f}$ \\ Ghassan Baidas $^{g}$ Rashed Al-Hamdan ${ }^{\mathrm{h}}$ Shaheed Zubair ${ }^{\mathrm{i}}$ Lukman Thalib $^{\mathrm{b}}$ \\ Departments of a Medicine and ${ }^{\mathrm{b}}$ Community Medicine and Biostatistics, Faculty of Medicine, Kuwait University, \\ ${ }^{\mathrm{c}}$ Mubarak Al-Kabeer Hospital, ${ }^{\mathrm{d}} \mathrm{Al}$-Amiri Hospital, ${ }^{\mathrm{e}} \mathrm{Al}$-Adan Hospital, ${ }^{\mathrm{f}} \mathrm{Al}$-Farwaniya Hospital, ${ }^{\mathrm{g}} \mathrm{Al}-\mathrm{Sabah}$ Hospital, \\ ${ }^{\mathrm{h}} \mathrm{Al}-\mathrm{Jahra} \mathrm{Hospital}$ and 'Kuwait Oil Company Hospital, Kuwait
}

\section{Key Words}

Myocardial infarction - Unstable angina - Acute coronary syndromes $\cdot$ Middle East $\cdot$ Kuwait $\cdot$ Risk factors $\cdot$ Registry

\begin{abstract}
Objectives: To identify the characteristics of patients with acute coronary syndromes (ACS), their hospital management and in-hospital outcomes, through a prospective registry system in Kuwait. Subjects and Methods: A registry involving all 7 general hospitals in Kuwait was set up. Consecutive patients diagnosed as having ACS over a period of 6 months were enrolled. Results: Of 2,129 patients enrolled, 718 (34\%) had ST segment elevation myocardial infarction (STEMI), 576 (27\%) non-ST segment elevation myocardial infarction (NSTEMI) and 835 (39\%) unstable angina (UA). Thrombolytic therapy was used in 556 (77\%) patients with STEMI. The median time from diagnostic electrocardiogram to administration of thrombolytic therapy was $38 \mathrm{~min}$. Almost all patients with $\mathrm{ACS}(2,050,96 \%)$ received aspirin during hospitalization. Only a minority received clopidogrel, 18 (3\%) STEMI, 36 (6\%) NSTEMI and 96 (12\%) UA patients. The use of glycoprotein Ilb/Illa antagonists was minimal (38 patients, $2 \%)$. $\beta$-Blockers were used in 1,473 (69\%) patients,
\end{abstract}

while 982 (46\%) received angiotensin-converting enzyme inhibitors. Coronary angiography during hospitalization was performed in 119 (17\%), 120 (21\%) and 126 (15\%) patients with STEMI, NSTEMI and UA, respectively. In-hospital mortality occurred in 31 (4\%) myocardial infarction patients and 4 $(0.5 \%)$ UA patients $(p<0.0001)$. Conclusion: This registry has enabled us to determine the incidence and characteristics of ACS patients in Kuwait. It has also enabled us to identify some barriers that we need to overcome for the full implementation of published guidelines for the management of patients with ACS.

Copyright $\odot 2007$ S. Karger AG, Basel

\section{Introduction}

Acute coronary syndromes (ACS) are a leading cause of mortality and morbidity, both in Western and developing countries. The past decade has witnessed considerable progress in the treatment options for patients with ACS. Management guidelines are published to provide clinicians with evidence-based treatment strategies, proved to decrease the mortality and morbidity of patients with ACS, and improve both in-hospital and long-

\section{KARGER}

Fax +4161306 1234 E-Mail karger@karger.ch www.karger.com

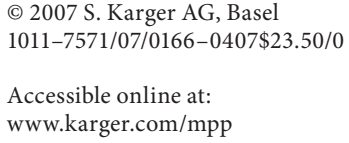

Prof. Mohammad Zubaid

Department of Medicine, Faculty of Medicine

PO Box 24923

Safat 13110 (Kuwait)

Tel. +965 531 9596, Fax +965 533 8907, E-Mail zubaid@hsc.edu.kw 
Table 1. Baseline characteristics and risk factors of patients

\begin{tabular}{lcclc}
\hline & $\begin{array}{l}\text { STEMI } \\
(\mathrm{n}=718)\end{array}$ & $\begin{array}{l}\text { NSTEMI } \\
(\mathrm{n}=576)\end{array}$ & $\begin{array}{l}\text { UA } \\
(\mathrm{n}=835)\end{array}$ & p value \\
\hline $\begin{array}{l}\text { Age, years } \\
\text { Age }\end{array}$ & $52.9 \pm 12.1$ & $59.5 \pm 12.5$ & $55.8 \pm 11.3$ & $<0.001$ \\
$\quad$ <55 years & $435(61)$ & $225(39)$ & $403(48)$ & $<0.001$ \\
$\quad 55-74$ years & $241(33)$ & $276(48)$ & $382(46)$ & $<0.001$ \\
$\quad$ M 75 years & $61(6)$ & $75(13)$ & $50(6)$ & $<0.001$ \\
Pren & $131(18)$ & $419(73)$ & $563(67)$ & $<0.001$ \\
Current smoker & $378(53)$ & $192(33)$ & $250(31)$ & $<0.001$ \\
Diabetes mellitus & $292(41)$ & $317(55)$ & $420(50)$ & $<0.001$ \\
Hypertension & $223(31)$ & $334(58)$ & $494(59)$ & $<0.001$ \\
Hyperlipidemia & $124(17)$ & $236(41)$ & $382(46)$ & $<0.001$ \\
\hline
\end{tabular}

Age values are presented as means \pm SD. Figures in parentheses are percentages. term outcomes for these patients $[1,2]$. However, there are limited data about the implementation of these guidelines into clinical practice in Kuwait. There are also limited data on the nature and distribution of ACS in Kuwait and the Middle East. Therefore, we set up the Kuwait Acute Coronary Syndromes (KACS) Registry, a prospective registry of all patients with ACS admitted to hospitals throughout Kuwait during a 6-month period. The objectives of the KACS Registry were to identify clinical and demographic characteristics, management practices and in-hospital outcomes of patients with ACS in Kuwait.

\section{Subjects and Methods}

The 7 general hospitals in Kuwait that admit ACS patients participated in this registry. These hospitals are Mubarak Al-Kabeer, Al-Amiri, Al-Adan, Al-Farwaniya, Al-Jahra, Al-Sabah and Kuwait Oil Company. At each hospital, designated physicians prospectively identified consecutive patients admitted with ACS over a period of 6 months, from December 2003 through May 2004. Several variables were collected, including patients' demographics, past medical history, diagnosis on admission, vital signs at presentation, diagnostic electrocardiogram (ECG), peak creatine kinase enzyme and creatine kinase MB isoenzyme, peak cardiac troponin I, blood sugar, fasting serum lipids, diagnosis on discharge, in-hospital and discharge medications, in-hospital outcomes including recurrent ischemia, reinfarction, heart failure and cardiogenic shock, and in-hospital mortality. Hypertension was defined by one of the following criteria: history of hypertension diagnosed and treated with medication, diet and/or exercise; blood pressure greater than $140 \mathrm{~mm} \mathrm{Hg}$ systolic or $90 \mathrm{~mm} \mathrm{Hg}$ diastolic on at least 2 occasions; current use of antihypertensive therapy. Hyperlipidemia was defined as having a history of elevated cholesterol and triglycerides diagnosed and/or treated by a physician. Data forms were checked for completeness at a nation- al coordinating center and were returned for corrections to the participating hospitals when necessary.

The diagnosis of different types of ACS was based on the definitions of the American College of Cardiology (ACC) [3]. Cardiac biomarkers were measured locally at each hospital laboratory, using its own assays and reference ranges. Patient care at each participating hospital was performed according to usual practice, independent of the KACS Registry. For the diagnosis of unstable angina (UA) to be made, the following criteria were necessary. (1) Clinical presentation: angina that occurred at rest and was prolonged, usually lasting more than $20 \mathrm{~min}$; new-onset angina of at least Canadian Cardiovascular Society (CCS) class III severity or recent acceleration of angina reflected by an increase in severity of at least 1 CCS class to at least CCS class III. (2) The biochemical cardiac markers had to be within the normal range or slightly elevated, but not reaching the range at which myocardial infarction (MI) occurs. (3) The ECG at presentation had to have ST segment depression or T wave inversion; if there were no ECG changes at presentation, then one of the following was required: a history of MI, positive exercise stress test or previous angiogram showing significant coronary artery disease.

\section{Statistical Analysis}

Baseline and clinical characteristics of patients were presented as frequencies and means. Continuous variables were compared using the Mann-Whitney $U$ test and categorical variables were compared using the Z-test of proportion; a value of $\mathrm{p}<0.05$ was considered statistically significant. All data analyses were carried out using SPSS, version 10.0.

\section{Results}

\section{Patient Characteristics}

Of the 2,129 patients enrolled, the final discharge diagnosis was ST segment elevation MI (STEMI) in 718 patients (34\%), non-ST segment elevation MI (NSTEMI) in 
$576(27 \%)$ and UA in 835 (39\%). The baseline characteristics and risk factors of the patients are listed in table 1. Compared to other ACS patients, those diagnosed as having STEMI were significantly younger, more often male and often cigarette smokers, but less often with a history of diabetes, hypertension or hyperlipidemia. A history of previous MI was more frequent among the patients with NSTEMI $(200,35 \%)$ and UA $(255,31 \%)$, than among those with STEMI $(132,18 \%)$.

There was a good agreement between the provisional diagnosis on admission and the final diagnosis at discharge in patients with STEMI and UA. However, in most patients with NSTEMI, the final diagnosis did not match the provisional admission (fig. 1).

\section{Management Practices}

The in-hospital and discharge medications are shown in table 2. During the first $24 \mathrm{~h}$ of hospitalization, 2,050 (96\%) patients with ACS received aspirin and 150 (7\%) received clopidogrel. Unfractionated heparin was used in 1,732 (81\%) patients, mostly in those with STEMI. A small number of patients $(171,13 \%)$ received low-molecularweight heparin. The use of glycoprotein IIb/IIIa antagonists was minimal $(38,2 \%)$. The prescription of $\beta$-blockers at discharge was higher $(1,631,77 \%)$ than that of angiotensin-converting enzyme (ACE) inhibitors $(1,149$, $54 \%)$.

Of 718 patients with STEMI, $556(77 \%)$ received thrombolytic therapy. Among STEMI patients eligible for thrombolytic therapy (hospital presentation within $12 \mathrm{~h}$ of symptom onset in the absence of contraindications for thrombolysis), the thrombolysis rate was $91 \%$. The median time from the first diagnostic ECG to administration of thrombolytic therapy was $38 \mathrm{~min}$.

Noninvasive and invasive diagnostic and therapeutic procedures during hospitalization are shown in figure 2 . Coronary angiography was performed more frequently in patients with NSTEMI $(120,21 \%)$ compared to those with STEMI $(119,17 \%)$ or UA $(126,15 \%)$. We identified $118(6 \%)$ patients with non-ST segment elevation ACS, considered to be at high risk for future cardiac events. These patients had ST segment depression on the diagnostic ECG, left ventricular failure at presentation and elevated troponin levels. Only 18 (15\%) of these high-risk patients were transferred for coronary angiography during their hospital stay.

\section{Hospital Outcomes}

In-hospital outcomes are listed in table 3. The mortality rate was $4 \%$ for MI patients and $0.5 \%$ for UA patients

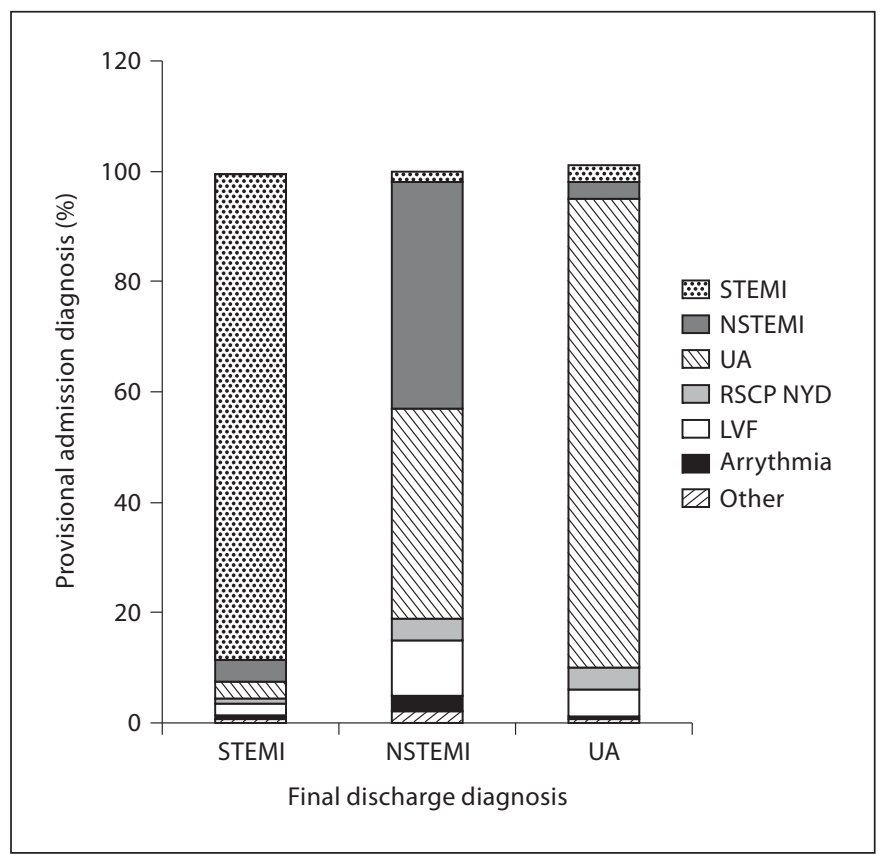

Fig. 1. Relation between provisional diagnosis on admission and final diagnosis at hospital discharge. RSCP NYD = Retrosternal chest pain not yet diagnosed; LVF = left ventricular failure.

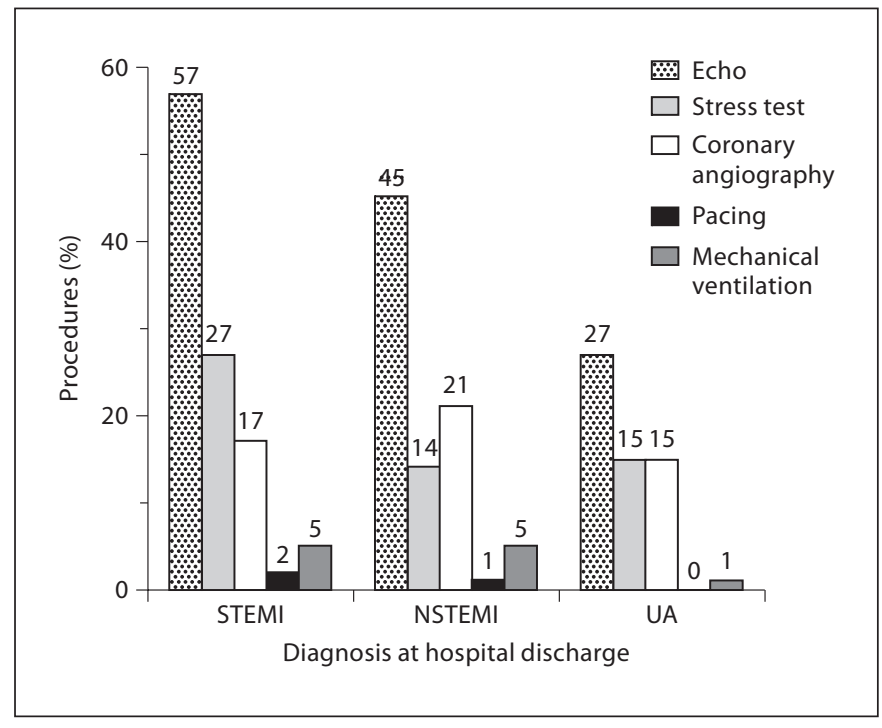

Fig. 2. Procedures during hospital stay.

( $p<0.0001)$. Similarly, complications were more common among patients diagnosed as having MI compared to those diagnosed as having UA. Recurrent ischemia and congestive heart failure occurred more frequently in pa- 
Table 2. Medications during first day of hospital stay and at discharge

\begin{tabular}{|c|c|c|c|c|}
\hline & $\begin{array}{l}\text { STEMI } \\
(\mathrm{n}=718)\end{array}$ & $\begin{array}{l}\text { NSTEMI } \\
(\mathrm{n}=576)\end{array}$ & $\begin{array}{l}\text { UA } \\
(n=835)\end{array}$ & $\mathrm{p}$ value \\
\hline \multicolumn{5}{|l|}{ In-hospital } \\
\hline Aspirin & $704(98)$ & $550(96)$ & $796(95)$ & 0.009 \\
\hline Clopidogrel & $18(3)$ & $36(6)$ & $96(12)$ & $<0.001$ \\
\hline Unfractionated heparin & $655(91)$ & $467(81)$ & $610(73)$ & $<0.001$ \\
\hline LMWH & $35(5)$ & $81(14)$ & 155 (19) & $<0.001$ \\
\hline Tirofiban & $4(1)$ & $25(4)$ & $9(1)$ & $<0.001$ \\
\hline$\beta$-Blocker & $500(70)$ & $362(63)$ & $611(73)$ & $<0.001$ \\
\hline ACE inhibitor & $332(46)$ & $269(47)$ & $382(46)$ & 0.938 \\
\hline AIIRB & $4(1)$ & $13(2)$ & $41(5)$ & $<0.001$ \\
\hline Nitrates & $551(77)$ & $515(89)$ & $768(92)$ & $<0.001$ \\
\hline Calcium blocker & $29(4)$ & $100(17)$ & $175(21)$ & $<0.001$ \\
\hline Statin & $499(70)$ & $439(76)$ & $607(73)$ & 0.03 \\
\hline Spironolactone & $12(2)$ & $20(4)$ & $30(4)$ & 0.05 \\
\hline \multicolumn{5}{|l|}{ At hospital discharge } \\
\hline Aspirin & $670(98)$ & $517(94)$ & $779(94)$ & 0.02 \\
\hline Clopidogrel & $40(6)$ & $81(15)$ & $139(17)$ & 0.001 \\
\hline Unfractionated heparin & $49(7)$ & $56(10)$ & $44(5)$ & 0.005 \\
\hline LMWH & $21(3)$ & $33(6)$ & $37(5)$ & 0.044 \\
\hline$\beta$-Blocker & $576(84)$ & $407(74)$ & $648(78)$ & $<0.001$ \\
\hline ACE-inhibitor & $437(64)$ & $310(56)$ & $402(48)$ & $<0.001$ \\
\hline AIIRB & $6(1)$ & $19(3)$ & $54(7)$ & $<0.001$ \\
\hline Nitrates & $508(74)$ & $461(83)$ & $681(82)$ & $<0.001$ \\
\hline Calcium blocker & $55(8)$ & $145(26)$ & $225(27)$ & $<0.001$ \\
\hline Statin & $394(57)$ & $370(67)$ & $528(64)$ & $<0.001$ \\
\hline Other lipid lowering & $188(27)$ & $100(18)$ & $145(17)$ & $<0.001$ \\
\hline Spironolactone & $23(3)$ & $22(4)$ & $33(4)$ & 0.716 \\
\hline
\end{tabular}

Figures in parentheses are percentages. LMWH = Low-molecular-weight heparin; $\mathrm{ACE}=$ angiotensin-converting enzyme; $\mathrm{AIIRB}=$ angiotensin II receptor blocker.

Table 3. Hospital outcomes

\begin{tabular}{lcccr}
\hline & $\begin{array}{l}\text { STEMI } \\
(\mathrm{n}=718)\end{array}$ & $\begin{array}{l}\text { NSTEMI } \\
(\mathrm{n}=576)\end{array}$ & $\begin{array}{l}\text { UA } \\
(\mathrm{n}=835)\end{array}$ & p value \\
\hline Recurrent ischemia & $130(18)$ & $131(23)$ & $129(5)$ & 0.002 \\
Infarction & $25(4)$ & $14(2)$ & $4(1)$ & $<0.001$ \\
CHF & $65(9)$ & $81(14)$ & $22(3)$ & $<0.001$ \\
Ventilation & $32(5)$ & $26(5)$ & $6(1)$ & $<0.001$ \\
Inotrope & $43(6)$ & $24(4)$ & $8(1)$ & $<0.001$ \\
Cardiogenic shock & $35(5)$ & $17(3)$ & $4(1)$ & $<0.001$ \\
Pacing & $16(2)$ & $3(1)$ & $0(0)$ & $<0.001$ \\
Stroke & $2(0.3)$ & $2(0.3)$ & $1(0.1)$ & 0.657 \\
VT/VF requiring Trx & $39(5)$ & $11(2)$ & $1(0.1)$ & $<0.001$ \\
AF/SVT requiring Trx & $19(3)$ & $22(4)$ & $12(1)$ & $<0.001$ \\
Major bleed & $8(1)$ & $4(1)$ & $1(0.1)$ & $<0.001$ \\
Hospital mortality & $31(4)$ & $23(4)$ & $4(1)$ & $<0.001$ \\
Median length of hospital stay, days & 6 & 6 & 4 & $<0.001$ \\
\hline
\end{tabular}

Figures in parentheses are percentages. $\mathrm{CHF}=$ Congestive heart failure; VT/VF = ventricular tachycardia/fibrillation; $\operatorname{Trx}=$ treatment; AF/SVT = atrial fibrillation/supraventricular tachycardia. 
tients with NSTEMI, while reinfarction and cardiogenic shock resulted more frequently in patients with STEMI. Stroke was a rare event in all patients with ACS. The median length of hospital stay was 6 days for both STEMI and NSTEMI patients and 4 days for patients with UA.

\section{Discussion}

This is the first prospective nationwide registry undertaken in Kuwait, in which the full spectrum of ACS is represented. Because all hospitals in Kuwait that admit ACS patients participated in this registry, the delivered data are presumed to accurately portray patient characteristics and clinical practice in Kuwait. Since this registry was conducted in 2004, it has the advantages of enrolling patients according to the new MI definition utilizing troponin, and of reporting on the use of medications advised by the latest ACC/American Heart Association (AHA) guidelines [1, 2].

When compared to patients from developed countries, our ACS patients are about a decade younger $[4,5]$. This can be explained partly by the fact that in Kuwait, population structure is young [6]. The prevalence of reported history of diabetes in Kuwait is about twice that reported from registries of North America and Europe [5, 7], reflecting the relatively high prevalence of diabetes in Kuwait [8].

This registry provided an opportunity to explore the relationship between provisional diagnosis on admission and final diagnosis at hospital discharge. In contrast to patients with STEMI, those with NSTEMI were often not diagnosed accurately at the time of admission (fig. 1). Thus, improvement in early diagnostic assessment and risk stratification is needed for patients presenting with NSTEMI.

It is recommended in the ACC/AHA guidelines of 2004 [1] that patients with STEMI or new left bundle branch block receive aspirin and be reperfused by either thrombolysis or primary percutaneous coronary intervention within $30 \mathrm{~min}$ of presentation to the hospital. The use of $\beta$-blockers, ACE inhibitors and statins is also recommended within $24 \mathrm{~h}$ of MI diagnosis [1]. Thrombolysis is the primary method of reperfusion in hospitals in Kuwait. In this study, there was a high rate of use of thrombolytic therapy, $91 \%$ of the thrombolysis-eligible group received such therapy. Only $9 \%$ of the eligible patients did not receive reperfusion therapy, contrary to $30 \%$ in the Global Registry of Acute Coronary Events (GRACE) [5] and 24\% in the US National Registry of
Myocardial Infarction [4]. There are several possible explanations for this difference in practice. The fact that our patients are young and less at risk of bleeding from thrombolytic therapy may cause the treating physicians to be less hesitant in administering such therapy. Another possible explanation is the fact that the critical care units (CCUs) in Kuwait are managed by cardiologists and not internists.

However, there was a considerable in-hospital delay in administering this treatment to our patients. The median time from the first diagnostic ECG to thrombolysis was $38 \mathrm{~min}$. In a previous registry, carried out in 2002, thrombolytic therapy was administered in the CCUs [9]. In the current registry, most hospitals administered thrombolytic therapy in the emergency departments rather than CCUs. We believe that this resulted in shortening the time interval for thrombolysis administration by $7 \mathrm{~min}$ utes. However, it remains an unacceptably long time interval. The door-to-needle time needs to be shortened substantially to maximize the benefit of thrombolytic therapy. Improving the time lag from arrival at the hospital to thrombolysis administration would require coordinated efforts by the emergency medical system, the emergency departments and cardiology divisions of the hospitals concerned.

As recommended in the ACC/AHA guidelines of 2002 for the management of non-ST elevation ACS [2], patients should receive aspirin, some form of heparin, clopidogrel and $\beta$-blockers [2]. In addition, high-risk patients should receive a glycoprotein IIb/IIIa antagonist and undergo coronary angiography. A substantial proportion of ACS patients in our registry, including the high-risk non-ST segment elevation ACS subgroup, did not undergo in-patient coronary angiography. This may be explained by the unavailability of onsite catheterization laboratories at the participating hospitals. Studies have shown that hospitals without onsite catheterization laboratories have lower rates of coronary angiography and percutaneous coronary intervention [10]. The availability of only one catheterization facility serving all of Kuwait limits the use of coronary angiography.

The use of well-established treatments like aspirin, some form of heparin, $\beta$-blockers and ACE inhibitors was acceptable and in concordance with the guidelines [1, 2]. However, the use of clopidogrel and glycoprotein IIb/ IIIa antagonists was very low. The delay between recommendations of the guidelines and the implementation of new therapies into routine clinical practice is well recognized and may explain the low rate of use of these 2, comparatively newer, therapies [11]. 
The $4 \%$ hospital mortality noted in this study for STEMI and NSTEMI patients is comparable to the $6-8 \%$ reported in Western registries [11]. The reason for this relatively low hospital mortality, despite high rate of diabetes, is not clear. Possible explanations include younger age and high rate of use of reperfusion (thrombolytic) therapy in this study population.

The main limitation of this registry is the absence of long-term follow-up and the absence of follow-up of patients who were referred to catheterization during their hospital stay.

\section{Conclusion}

This registry has enabled us to determine the incidence and characteristics of ACS patients in Kuwait. It has also enabled us to identify some barriers that we need to overcome for the full implementation of published guidelines for the management of patients with ACS.

\section{Acknowledgments}

We would like to thank Merck Sharp and Dohme and the Kuwait Oil Company for their financial support to the KACS Registry. We would also like to thank Miss Rihab Moneer for her help in the editorial preparation of the manuscript.

\section{References}

1 Antman EM, Anbe DT, Armstrong PW, Bates ER, Green LA, Hand M, Hochman JS, Krumholz HM, Kushner FG, Lamas GA, Mullany CJ, Ornato JP, Pearle DL, Sloan MA, Smith SC Jr: ACC/AHA guidelines for the management of patients with ST-elevation myocardial infarction - executive summary. J Am Coll Cardiol 2004;44:671-719.

-2 Braunwald E, Antman EM, Beasley JW, Califf RM, Cheitlin MD, Hochman JS, Jones RH, Kereiakes D, Kupersmith J, Levin TN, Pepine CJ, Schaeffer JW, Smith EE 3rd, Steward DE, Theroux P, Gibbons RJ, Alpert JS, Faxon DP, Fuster V, Gregoratos G, Hiratzka LF, Jacobs AK, Smith SC Jr: ACC/AHA 2002 guideline update for the management of patients with unstable angina and non-ST-segment elevation myocardial infarction - summary article. J Am Coll Cardiol 2002;40: 1366-1374.

$\checkmark 3$ Cannon CP, Battler A, Brindis RG, Cox JL, Ellis SG, Every NR, Flaherty JT, Harrington RA, Krumholz HM, Simoons ML, Van De Werf FJ, Weintraub WS, Mitchell KR, Morrisson SL, Brindis RG, Anderson HV, Cannom DS, Chitwood WR, Cigarroa JE, Collins-Nakai RL, Ellis SG, Gibbons RJ, Grover FL, Heidenreich PA, Khandheria BK, Knoebel SB, Krumholz HL, Malenka DJ, Mark DB, Mckay CR, Passamani ER, Radford MJ, Riner RN, Schwartz JB, Shaw RE, Shemin RJ, Van Fossen DB, Verrier ED, Watkins MW, Phoubandith DR, Furnelli T: American College of Cardiology key data elements and definitions for measuring the clinical management and outcomes of patients with acute coronary syndromes: a report of the American College of Cardiology Task Force on Clinical Data Standards (Acute Coronary Syndromes Writing Committee). J Am Coll Cardiol 2001;38:2114-2130.
4 Wiviott SD, Morrow DA, Frederick PD, Antman EM, Braunwald E: Application of the thrombolysis in myocardial infarction risk index in non-ST-segment elevation myocardial infarction: evaluation of patients in the National Registry of Myocardial Infarction. J Am Coll Cardiol 2006;47:1553-1558.

5 Steg PG, Goldberg RJ, Gore JM, Fox KA, Eagle KA, Flather MD, Sadiq I, Kasper R, Rushton-Mellor SK, Anderson FA; GRACE Investigators: Baseline characteristics, management practices, and in-hospital outcomes of patients hospitalized with acute coronary syndromes in the Global Registry of Acute Coronary Events (GRACE). Am J Cardiol 2002;90:358-363.

6 Health Kuwait, ed 32. Kuwait, Kuwait Health and Vital Statistics Division, Ministry of Health, 1995.

7 Fonarow GC, French WJ, Parsons LS, Sun H, Malmgren JA: Use of lipid-lowering medications at discharge in patients with acute myocardial infarction: data from the $\mathrm{Na}$ tional Registry of Myocardial Infarction 3. Circulation 2001;103:38-44.
8 Abdella N, Al Arouj M, Al Nakhi A, Al Assoussi A, Moussa M: Non-insulin-dependent diabetes in Kuwait: prevalence rates and associated risk factors. Diabetes Res Clin Pract 1998;42:187-196.

-9 Zubaid M, Rashed WA, Husain M, Mohammad BA, Ridha M, Basharuthulla M, Rezq MA, Smid J, Thalib L: A registry of acute myocardial infarction in Kuwait: patient characteristics and practice patterns. Can J Cardiol 2004;20:783-787.

10 Fox KA, Goodman SG, Klein W, Brieger D, Steg PG, Dabbous O, Avezum A: Management of acute coronary syndromes: variations in practice and outcome; findings from the Global Registry of Acute Coronary Events (GRACE). Eur Heart J 2002;23:11771189.

- 11 Fox KA, Goodman SG, Anderson FA Jr, Granger CB, Moscucci M, Flather MD, Spencer F, Budaj A, Dabbous OH, Gore JM; GRACE Investigators: From guidelines to clinical practice: the impact of hospital and geographical characteristics on temporal trends in the management of acute coronary syndromes. The Global Registry of Acute Coronary Events (GRACE). Eur Heart J 2003;24:1414-1424. 